\title{
3D Finite Element Modeling of Single Bolt Connections under Static and Dynamic Tension Loading
}

\author{
Emily Guzas, Kevin Behan, and John Davis \\ Division Newport (NUWCDIVNPT), US Naval Undersea Warfare Center, 1176 Howell Street, Newport, RI 02841, USA \\ Correspondence should be addressed to Emily Guzas; emily.guzas@navy.mil
}

Received 1 May 2014; Accepted 4 August 2014

Academic Editor: Senthil S. Vel

Copyright (C) 2015 Emily Guzas et al. This is an open access article distributed under the Creative Commons Attribution License, which permits unrestricted use, distribution, and reproduction in any medium, provided the original work is properly cited.

\begin{abstract}
The Naval Undersea Warfare Center has funded research to examine a range of finite element approaches used for modeling bolted connections subjected to various loading conditions. Research focused on developing finite element bolt representations that were accurate and computationally efficient. A variety of finite element modeling approaches, from detailed models to simplified ones, were used to represent the behavior of single solid bolts under static and dynamic tension loading. Test cases utilized models of bolted connection test arrangements (static tension and dynamic tension) developed for previous research and validated against test data for hollow bore bolts (Behan et al., 2013). Simulation results for solid bolts are validated against experimental data from physical testing of bolts in these load configurations.
\end{abstract}

\section{Introduction}

The Navy relies heavily on finite element analysis for assessments of various systems and components during stowage and handling operations, as well as during potential shock events. Analytical assessments usually involve finite element models that are necessarily very complex in order to adequately represent the overall system response. These systems often include bolted connections, which must be incorporated into the finite element models due to requirements to evaluate the response of any bolts to the external loading of interest. Given that the level of detail necessary to accurately model these systems creates finite constraints on model size and run time, the bolted connections in these systems are rarely modeled in a detailed fashion. Of course, the quality of results from a structural assessment depends on the accuracy of the underlying bolt representations. Thus, the focus of the current research is to examine a range of finite element modeling techniques used for representing bolted connections subjected to various loading conditions. Numerous finite element modeling approaches, from detailed models to simplified ones, were used to model the behavior of single bolts under tension loading in as-tested physical configurations, and results were compared to experimental data.

\section{Literature Review}

Previous research on simplified approaches to connection modeling has focused on finite element modeling of bolted connections with validation through experiment, although much of this research has focused on non-Navy applications. This research falls into a variety of categories including simplified connection models for applications ranging from progressive collapse to pipe structure behavior and to plate structure behavior.

In the field of progressive collapse modeling, work has focused on developing simplified models, or macromodels, of steel and concrete beam-column connections using combinations of beam and discrete spring elements [1-6]. These macromodels were used to examine the progressive collapse resistance of a variety of $2 \mathrm{D}$ frame [1-3] and 3D building structures [4-6].

Prior research on simplified modeling of joints in pipe structures was carried out by Luan et al. [7]. They developed a simplified nonlinear model with bilinear springs to model the bolted flange joints in cylindrical pipe structures. They compared the performance of this model against dynamic impact loading test data, as well as results using a simple beam 


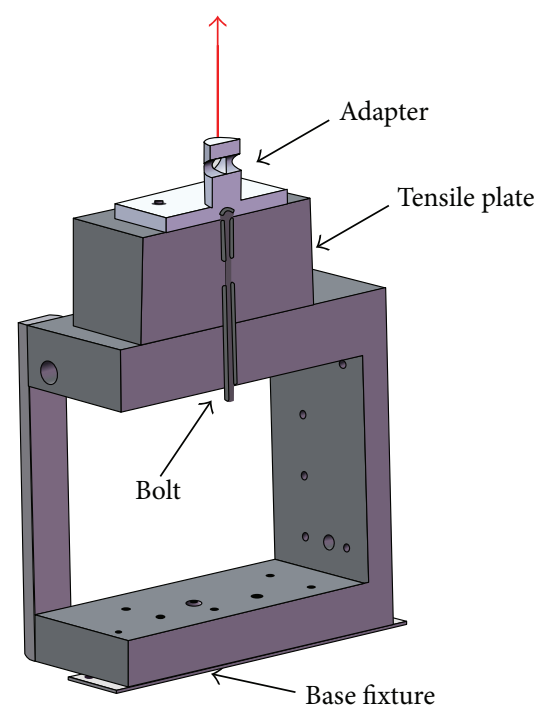

(a)

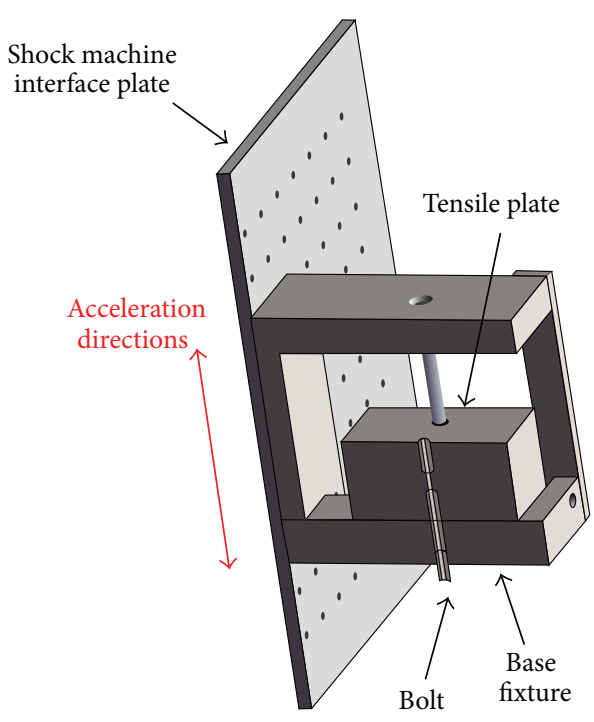

(b)

FIGURE 1: Section view of (a) static tension test and (b) dynamic tension test.

model of the entire joint and a detailed finite element model of the pipe, joint, and bolts.

Previous research has been conducted on simplified modeling of bolted connections in generic or plate structures [3, 8-10]. Kwon et al. [8] modeled bolt behavior using a detailed model and a selection of simplified "practical" models for both static loading and modal analysis experiments. Kim et al. [9] modeled bolt behavior using four different approaches: a solid bolt model, a coupled bolt model, a spider bolt model, and a no-bolt model. Their detailed solid-element based model with contact and their simplified coupled bolt model, which used a single beam element with degree-of-freedom coupling between its nodes and the solid element nodes of the plates on their outermost surfaces, produced the most accurate results as compared to experimental results [9] for a static loading experiment of a simple lap joint.

Shi et al. [10] investigated a bolted joint where a thin plate was connected by a single bolt at each end to a thicker plate that was fixed to a main frame. They developed twelve simplified models, which were used to simulate a drop test where the middle of the thin plate was hit by an impactor. The best results using a simplified approach were produced using deformable shell elements to model the bolt-nut assembly, where the bending stiffness of the cylindrical shell had been set equal to that of the bolt shank and contact between the bolt shank and the plates was included.

A variety of work has carried out regarding detailed finite element modeling of bolted connections with validation through experiment. McCarthy et al. [11] and C. T. McCarthy and M. A. McCarthy [12] presented results on single-lap, single-bolt composite joints with titanium bolts. Base model development and validation against experimental strain gauge data from the joint surface and experimental joint stiffness data is discussed in [11], and C. T. McCarthy and M. A. McCarthy [12] examined the effects of bolt clearance on various aspects of joint behavior including joint stiffness, bolt rotation, bolt-hole contact area, stress distribution in the laminate, and the onset of failure. Prior research at NUWCDIVNPT, by Behan et al. [13], involved the development of highly detailed finite element models of bolt arrangements as tested in actual physical experiments, where model results compared favorably to experimental data for hollow bore bolts subjected to static and dynamic shear and tensile loading.

This work builds on previous work in that the detailed and simplified finite element models of a bolted connection were tested under both static and dynamic loading, for tensile test arrangements. The intent was to test the performance of a given set of finite element model representations of a single solid bolt under both static and dynamic tension loading conditions.

\section{Experimental Background}

Previous research detailed a set of experiments carried out to investigate bolt behavior under a variety of load types $[13,14]$ using hollow bore bolts. For the current research, similar experiments were performed with single noninstrumented solid bolts, and data from these tests were used for validation of the numerical results presented later in this paper. The bolt material was K-Monel K500, and the bolts themselves were $15.24 \mathrm{~cm}$ (6 in) long and $6.35 \mathrm{~mm}(0.25 \mathrm{in})$ in diameter, with a hex head and a standard $1.9 \mathrm{~cm}$ (0.75 in) length of 20UNC2A thread. Prior to loading, bolts were torqued to provide a pretension force equivalent to $2 / 3$ of the yield stress for K500, consistent with standard practice for naval structures.

The test configurations for the static tension and dynamic tension experiments are shown in Figures 1(a) and 1(b), respectively. During the static tension tests, the tensile force was applied to a tensile plate via an adapter connected to 
an Instron machine, as in Figure 1(a). For the dynamic tension tests, the test bracket was mounted onto an interface plate on a Lightweight Shock Machine (LWSM) [15], in the manner shown in Figure 1(b), and the impact of the LWSM vertical hammer on the interface plate produced accelerations in the directions shown in the figure. Further details of the testing are discussed in [13].

Although these experimental configurations are named for pure loading states, the authors realize that the loads actually imparted to the test bolts were not restricted to pure tension. Naming conventions follow from idealized test conditions, where each configuration has the potential to produce a loading state near to a pure one.

\section{Numerical Modeling}

Finite element models of the test fixture hardware and bolts were developed in ABAQUS, using ABAQUS/Standard for the static models and ABAQUS/Explicit for the dynamic models. To represent the constitutive behavior of the $\mathrm{K}$ Monel K500 of the bolts, a piecewise hardening model was fit to quasistatic tensile test data from coupons of the bolt material $[13,14]$, as shown in Figure 2. Mechanical and physical properties of the K500 material included a density of $8.435 \mathrm{~g} / \mathrm{cm}^{3}\left(7.893 \times 10^{-4} \mathrm{lb}-\mathrm{s}^{2} / \mathrm{in}^{4}\right)$, elastic modulus of $E=$ $178.2 \mathrm{GPa}\left(25.8 \times 10^{3} \mathrm{ksi}\right)$, Poisson's ratio of $v=0.32$, yield strength $(0.2 \%$ offset $)$ of $\sigma_{y}=729.5 \mathrm{MPa}(105.8 \mathrm{ksi})$, and ultimate strength of $\sigma_{u}=1367.2 \mathrm{MPa}(198.3 \mathrm{ksi})[13,14]$. The test fixture was modeled with linear elastic materials. In previous work, it was shown that rate-dependent material properties did not have a significant effect on simulation results for hollow bore bolts in the same experimental test configurations as those employed for the current research, where comparisons were made between models using quasistatic material properties and models with estimated ratedependent material properties at a strain rate of 1000/s [13]. Given that the hollow bore bolts and solid bolts experienced similar rates of deformation in the same experimental configurations (on the order of $25 / \mathrm{s}$ for the dynamic tension test, as quantified by the full resolution models described later in this paper), it is reasonable to use the quasistatic K500 material properties to represent the bolt material in simulations of both static and dynamic test configurations.

For the bolts themselves, element types were varied by modeling approach. The detailed models included continuum elements (C3D8 and C3D6) and the simplified models employed a variety of element types and kinematic constraints as described in a later section of this paper. For all models, the test fixture hardware was meshed with a combination of continuum elements (C3D8 and C3D6) $[16,17]$.

4.1. General Model Setup: Static Tension. For the static tension test configuration, two separate models were developed to represent the test fixture hardware, a full model and a submodel. The full model included all components contained within the test fixture, and the submodel included just the tensile plate and the upper portion of the test bracket, as shown in Figure 3. Preliminary studies were conducted

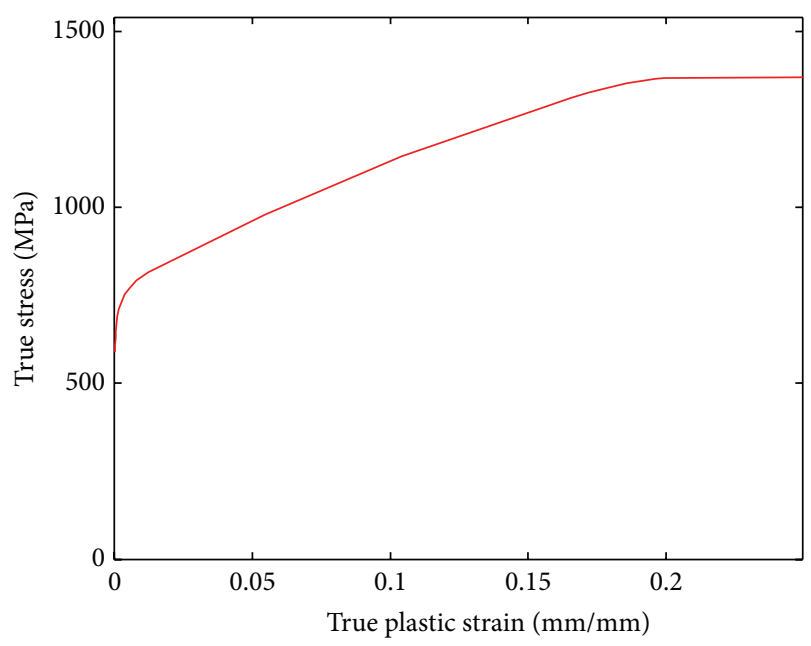

FIgURE 2: Material model for K-Monel K500.

comparing model results between the two models and it was found that there was extremely good agreement between both models for bolt axial force as measured at each increment in applied displacement. Thus, it was determined that the submodel was indeed sufficient to accurately capture the response of the tested configuration, and all subsequent analyses utilized the submodel in order to save computational time.

All of the numerical simulations of the static test included a static preload to $2 / 3$ of the yield stress for K500, consistent with the physical experiments. This pretightening force was applied in the first stage of the static analysis using the * PRETENSION SECTION, *SURFACE, and *STEP keywords, which worked together to incrementally develop a prescribed force over the bolt cross-section in the direction of the bolt longitudinal axis [16, 17]. After completion of the preload, the main static analysis proceeded with incremental application of displacement, where an arc length algorithm was used to guide the solution process. The arc length method in ABAQUS/Standard is a modified Riks algorithm that assumes proportional loading and calculates each increment in load proportionality factor based on the current arc length and increment in displacement [18-20]. Arc length parameters used in the static analyses included an initial arc length of $0.0254 \mathrm{~mm}$ (0.001 in), maximum length of $25.4 \mathrm{~mm}$ (1.0 in), and minimum length of $0.00127 \mathrm{~mm}\left(5 \times 10^{-5} \mathrm{in}\right)$. Displacements were incrementally applied to the top face of the tensile plate, in the sense shown in Figure 3, and the loaddisplacement response was calculated using the described arc length method.

4.2. General Model Setup: Dynamic Tension. For the dynamic tension test arrangement, a submodel approach was not sufficient to accurately capture the response of the tested configuration, given the eccentric nature of the applied loading to the test fixture and the finite compliance of the test fixture. Thus, the entire test fixture was explicitly modeled, as shown in Figure 4.

In the dynamic models, the static bolt preload was accounted for by using the ${ }^{*}$ INITIAL CONDITIONS keyword 


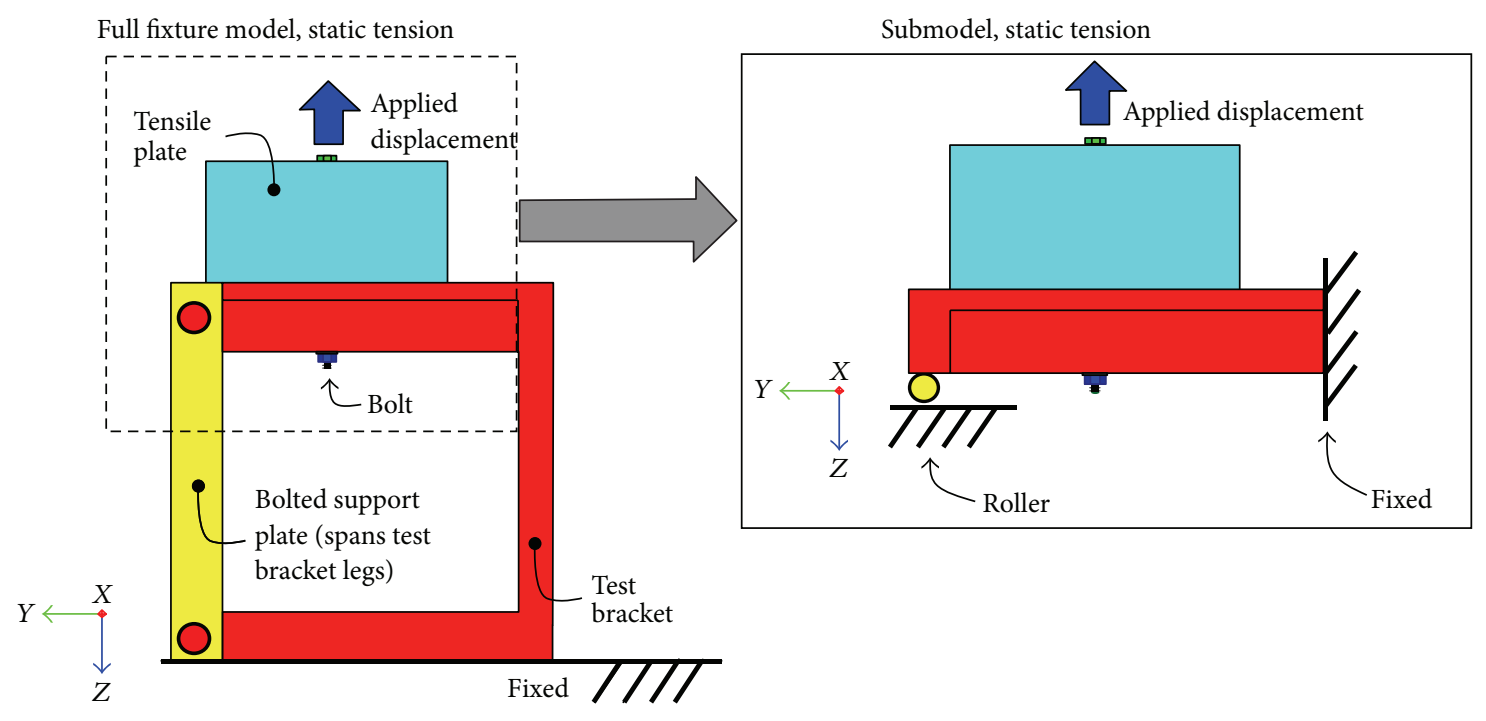

FIGURE 3: Submodel of static tension test.

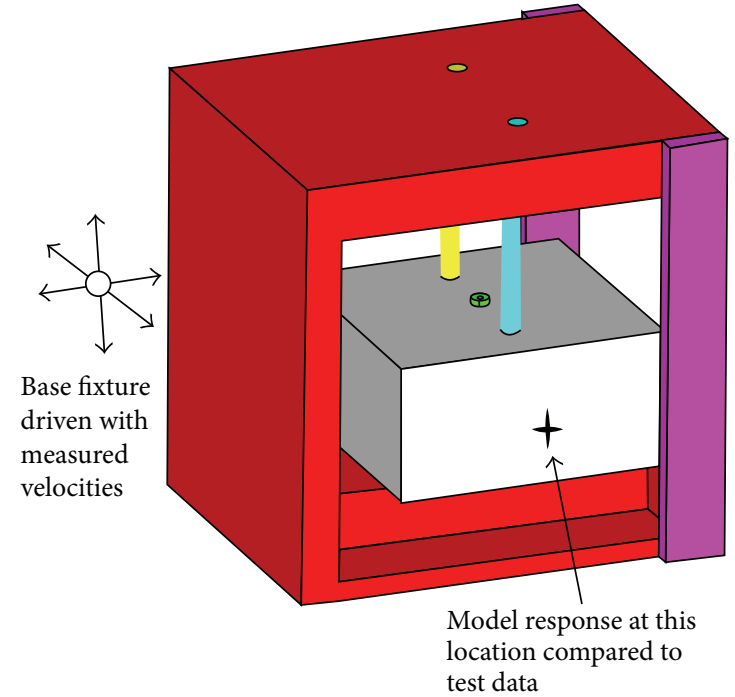

FIGURE 4: Schematic of the model for dynamic tension.

$[16,17]$ to apply an initial stress, equivalent to $2 / 3$ of the yield stress, to the bolt shank prior to the initiation of the transient dynamic analysis. During the dynamic analysis, the base fixture was driven with experimental velocity histories measured at the accelerometers mounted on the LWSM interface plate during the tests, as depicted in Figure 4. The main analysis was conducted using explicit time integration with automatic time stepping.

4.3. Detailed Bolt Models. For the detailed bolt models, the solid bolt was meshed with mostly C3D8 elements, with a few C3D6 elements $[16,17]$. Since it was observed that the bolt specimens typically failed in the threaded region, the threaded region of the detailed bolt models was modeled using the correct profile for 20UNC-2A thread [21], but with the simplification that the threads were arranged in a concentric pattern rather than the helical angle seen in the physical specimens. This modeling approach captured the effect of the reduced area in the threads without adding the complexity of producing a well-behaved mesh along a helically varying thread profile. Figures 5(a) and 5(b) show details of the tension test bolt mesh, which included 469,500 elements. The test fixture and tensile plate were modeled using a total of 146,100 elements, and the nut and washer were modeled with 46,300 elements.

In models that included the detailed bolt representations, contact between the washer and fixture, washer and nut, bolt head and tensile plate, and bolt threads and nut was modeled using tied contact for the static tension tests and finite sliding contact for the dynamic tension tests. Finite sliding contact was included between all other moving parts, as applicable (bolt body and tensile plate/bracket, tensile plate and test bracket, and tensile plate and guide rods).

4.4. Simplified Bolt Models. In addition to the detailed bolt models, five simplified bolt models were developed and investigated. Figure 6(a) depicts the outline of the detailed model, and Figures 6(b)-6(d) show the various simplified models. For brevity, Figure 6(b) actually represents simplified models \#1-3, since these models have similar pictorial representations. All simplified models used linear Timoshenko beam elements (element type B31), with uniform circular cross-sectional area, to represent the bolt body. Shear effects were accounted for using the * TRANSVERSE SHEAR option [17]. Along the shank of the bolt, the cross-section diameter was set to the nominal bolt diameter, $6.35 \mathrm{~mm}$ ( $0.25 \mathrm{in})$. In the threaded region, the beam elements were assigned a reduced cross-sectional area, with diameter set to the bolt thread minimum pitch diameter, $4.84 \mathrm{~mm}$ (0.19 in), except as noted.

4.4.1. Simplified Model \#1: Timoshenko Beams with Coupling Constraints, with a Hole. In this model, the body of the bolt 


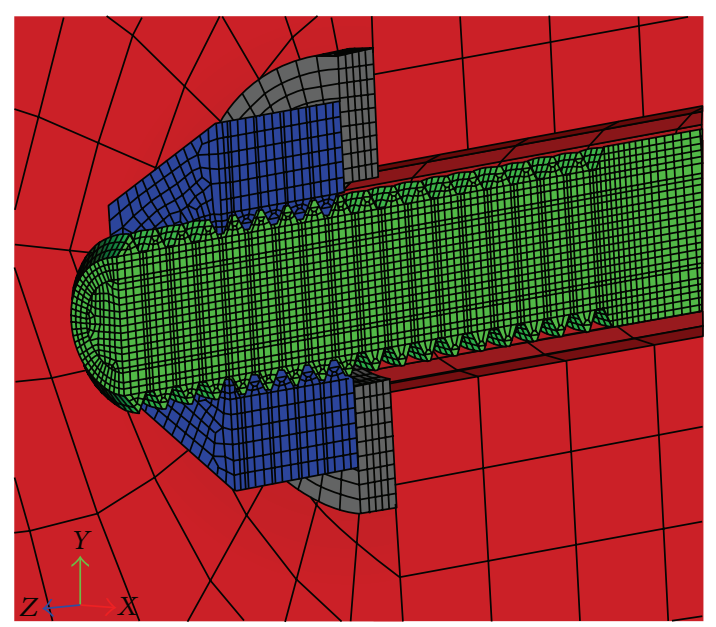

(a)

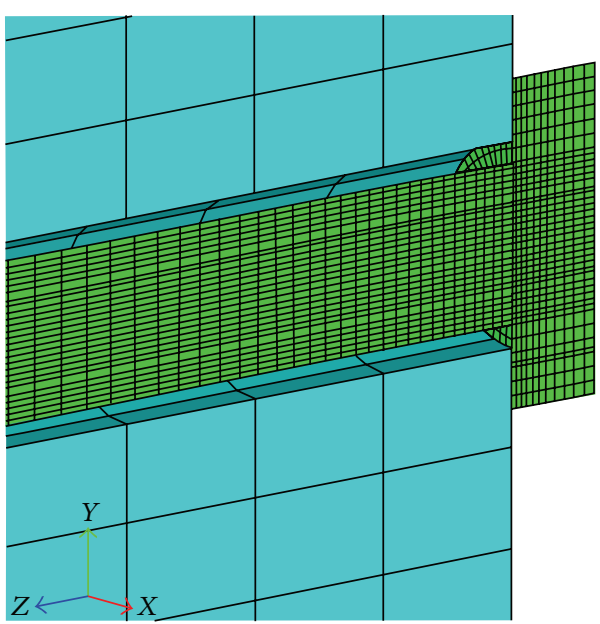

(b)

Figure 5: Section views of static tension finite element model, (a) detail of threaded end, and (b) detail at head.

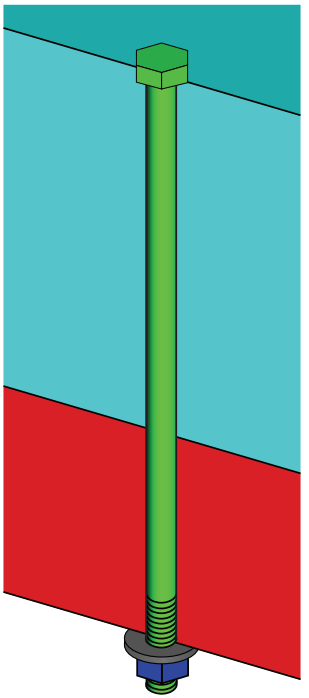

(a)

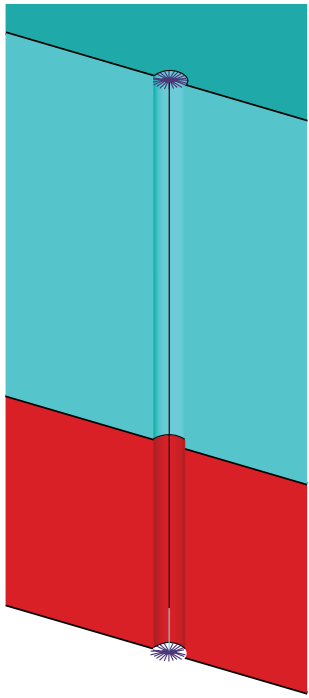

(b)

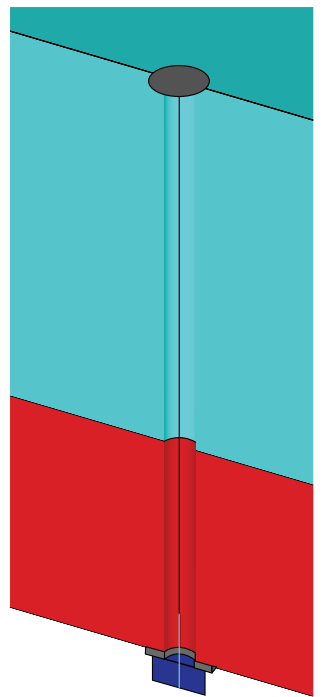

(c)

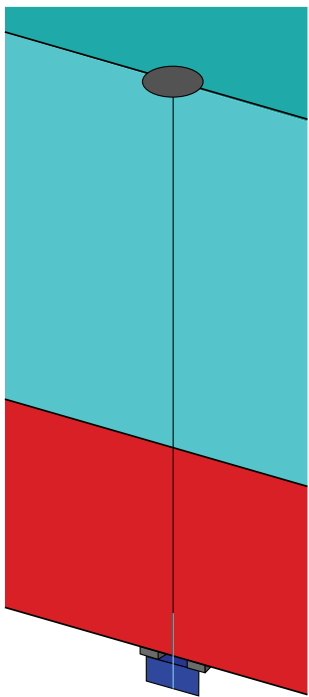

(d)

FIGURE 6: Static tension bolt modeling approaches, including (a) detailed model, (b) simplified model with end linkages (\#1-3), (c) simplified model with shell head and embedded end, with a hole (\#4), and (d) simplified model with shell head and embedded end, without a hole (\#5).

was modeled with 8 Timoshenko beam elements, with 6 elements to represent the bolt shank and 2 elements for the threaded region. The node at each end of the bolt was designated as an independent node, with degree-of-freedom coupling between this node and the surrounding plate nodes at the edge perimeter of the through hole. Degree-of-freedom coupling, for the translational degrees of freedom, was achieved via the keywords * KINEMATIC and * COUPLING [17].

\subsubsection{Simplified Model \#2: Timoshenko Beams with Multipoint} Constraints, with a Hole. This model was the same as model \#1 except that the degree-of-freedom coupling was achieved via multipoint constraints. The relevant keyword was * MPC, with the BEAM option [17].
4.4.3. Simplified Model \#3: Timoshenko Beams with Rigid Links, with a Hole. This model employed the same bolt body modeling approach as simplified models \#1 and \#2. However, the linkage at each end was achieved using rigid links. For the static tension tests, these elements were of type RB3D2 (available only in ABAQUS/Standard) and were associated with the keyword * RIGID BODY, and for the dynamic tension tests, truss elements of type T3D2 were used [17].

\subsubsection{Simplified Model \#4: Timoshenko Beams with Shell Head} and Embedded End, with a Hole. In this model, the body of the bolt was modeled with 10 Timoshenko beam elements, with 6 elements for the bolt shank and 4 elements for the threaded length of the bolt. The bolt head was modeled using S4 shell elements. For the static models, tied contact 
was defined between the shell elements of the head and the solid elements of the tensile plate in the vicinity of the bolt hole; however, the dynamic models all employed finite sliding contact with friction between these surfaces. The washer and the nut were explicitly modeled with solid elements and the endmost beam element in the threaded region shared its end nodes with the nut. It is important to note that this approach would be less complicated for bolted joints involving blind holes rather than a through hole like the one tested in the described experiments, because the endmost beam element could share nodes with the component at the bottom of the blind hole and no nut would have to be added to the simulation to provide the necessary constraint at the threaded end.

4.4.5. Simplified Model \#5: Timoshenko Beams with Shell Head and Embedded End, without a Hole. This model was the same as model \#4 except that the bolt hole was not explicitly modeled.

\section{Results and Discussion}

Comparisons were made between the numerical models and the experiments using global metrics, since local metrics such as strain data in or on the bolts were not available. For the static tests, load-displacement data served as the validation metric. For the dynamic tests, comparisons were made between experimental and simulated velocity data at the accelerometer location on the tensile plate, shown in Figure 4.

Static tension model simulations were performed on four cores of a local HPC cluster, where each core included a 2.67 GHz Intel Xeon processor and 32 GB RAM. Simulations with the detailed bolt model required approximately 3.8 hours of wall clock time to fully trace the nonlinear equilibrium load-displacement path to a maximum displacement of $4.1 \mathrm{~mm}(0.16 \mathrm{in})$. However, analyses with the simplified bolt models required $0.2-1.3$ hours of wall clock time to reach a maximum displacement of 4.7-2.2 $\mathrm{mm}$ (0.18-0.09 in). Dynamic tension analyses were carried out on the SGI Altix ICE (Spirit) HPC cluster at the US Air Force Research Laboratory (AFRL). Using 16 cores, the detailed bolt model required 260 hours of wall clock time to produce $150 \mathrm{~ms}$ of response. Running on 16 cores, the simplified bolt models needed 17-26 hours of clock time to yield $150 \mathrm{~ms}$ of response.

5.1. Static Tension. For all static tension models, force-displacement results were compared to experimental load-displacement data. In the numerical simulations, the axial force in the bolt at the midpoint of its grip length was recorded for each increment in applied displacement. For the detailed model, the force was calculated over a user-defined section using the *SECTION PRINT keyword [17]. Figure 7 shows a schematic of the cross-section location in the detailed static tension bolt model.

5.1.1. Detailed Model, Static Tension. Simulations of the static tension test arrangement using the detailed bolt model indicated that the bolt experienced high levels of deformation in the reduced-area region of the bolt threads, as shown in

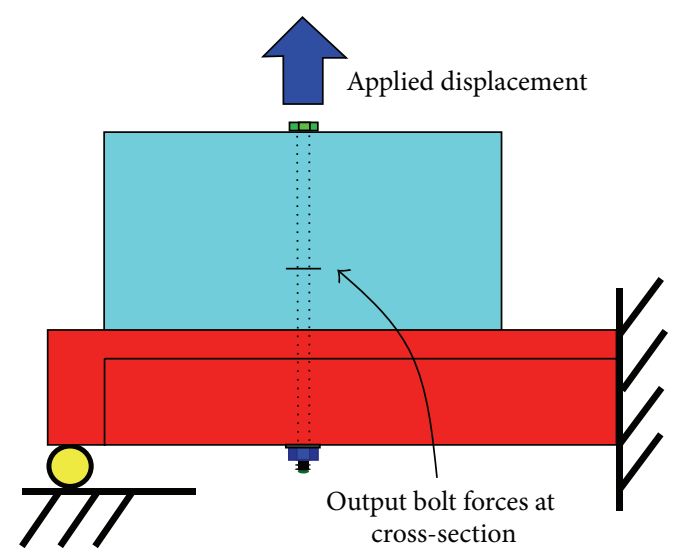

FIGURE 7: Schematic of axial force measurement location for detailed static tension model.

Figure 8. This is consistent with the physical experiments, where the bolts ultimately fractured at the threads. For the contours of effective plastic strain shown in Figure 8, the maximum effective plastic strain has been set at $20 \%$, corresponding with the strain at the ultimate stress of the tested K500 material $[13,14]$.

The detailed model force-displacement results are compared to experimental load-displacement data in Figure 9. The numerical results exhibit very good correlation with the experimental data.

5.1.2. Simplified Models, Static Tension. The force-displacement results for the simplified models can be grouped into two sets for models with similar end conditions. Simplified models \#1-3, which used kinematic constraints or rigid links as the linkages from the bolt body to the tensile plate and test bracket, produced similar results, as shown in Figure 10. When using the minimum pitch diameter in the threaded region, the results compare very well to experimental data.

Simplified models \#4-5 used shell elements to model the bolt head and the endmost beam element in the threaded region of the bolt body shared nodes with a detailed model of the nut. The presence of the bolt hole did not seem to matter for this case, as exhibited by the similarity in forcedisplacement results for simplified models \#4-5 shown in Figure 11. When using the minimum pitch diameter in the threaded region, the results compared well to experimental data.

A small parametric study was carried out using simplified model \#1 in order to ascertain the effect of the value used to model the bolt diameter in the threaded region. For this, three simulations were performed, each with a different bolt diameter assigned to the beam elements in the threaded region. The diameter values used corresponded to minimum (minor) thread pitch, $4.84 \mathrm{~mm}$ (0.19 in); basic thread pitch, $5.52 \mathrm{~mm}$ (0.22 in); and maximum (major) thread pitch, $6.35 \mathrm{~mm}$ (0.25 in). As shown in Figure 12, the best results were produced using minimum thread pitch. 


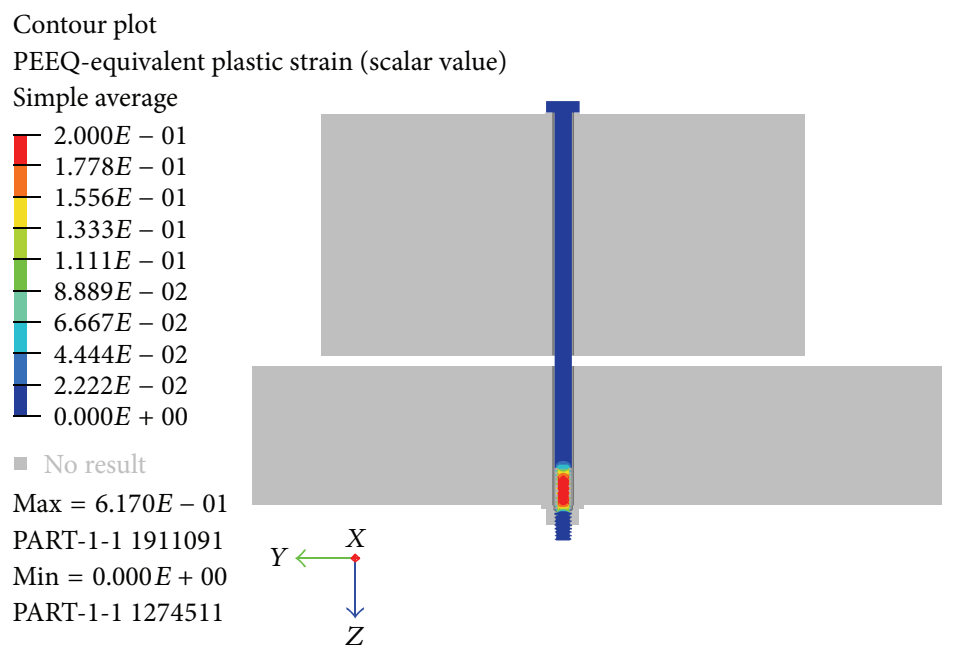

FIGURE 8: Contours of effective plastic strain at maximum applied displacement, detailed static tension model.

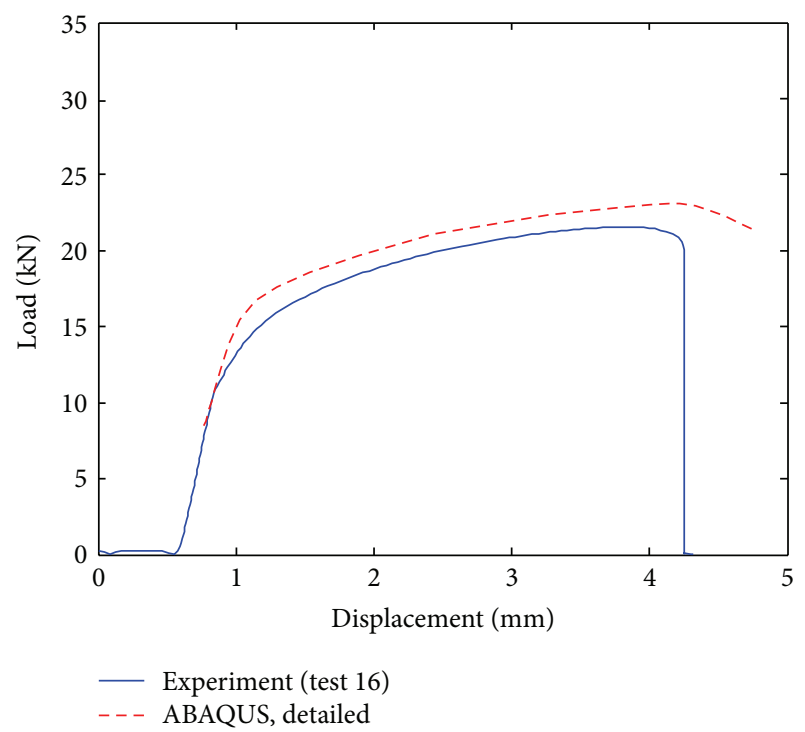

FIGURE 9: Force-displacement results for static tension test, detailed model.

5.2. Dynamic Tension. For the dynamic tension models, velocity histories at the accelerometer location on the tensile plate were compared to experimental accelerometer data. In the numerical simulations, the velocity in the direction of the hammer blow on the LWSM was recorded every $1 \mathrm{~ms}$ and the data were extracted from and averaged over several elements located on the tensile plate surface underneath the accelerometer footprint.

5.2.1. Detailed Model, Dynamic Tension. Similar to the static tension arrangement, results produced for the dynamic tension configuration using the detailed bolt model showed that the bolt experienced the highest levels of deformation in the reduced-area region of the bolt threads. Although

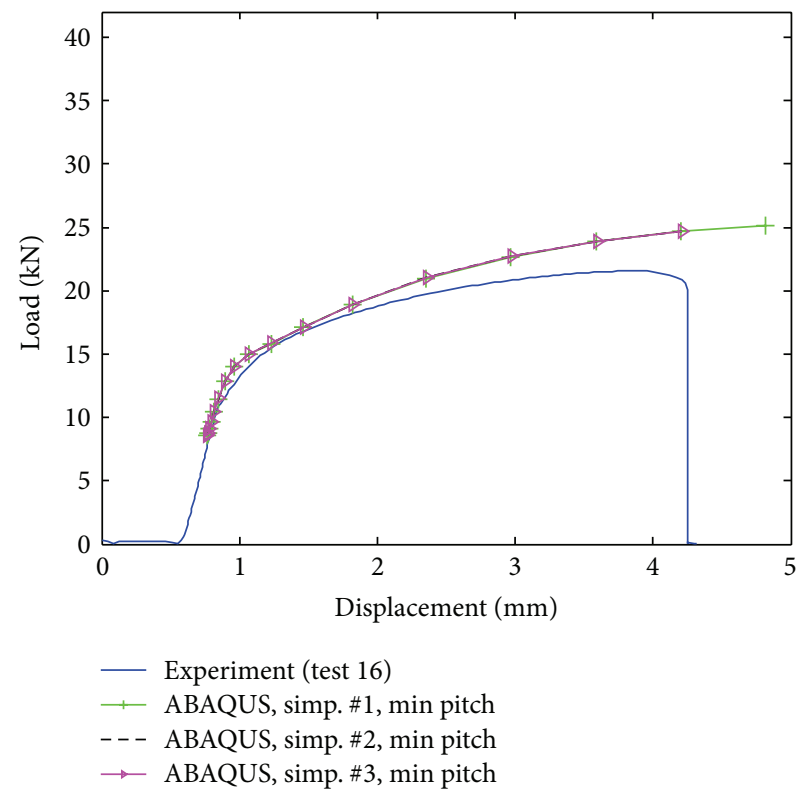

FIGURE 10: Force-displacement results for static tension test, simplified model \#1-3.

the tested bolt did not fail in the experiment, it did exhibit slight stretching and visible damage in the threads, which is consistent with the simulated results. Contours of effective plastic strain at $150 \mathrm{~ms}$ are shown in Figure 13, where the maximum effective plastic strain has been set at $20 \%$.

Velocity results at the accelerometer location obtained using the detailed model are plotted against the first $80 \mathrm{~ms}$ of experimental data in Figure 14. The simulated data compare well with the experimental data.

5.2.2. Simplified Models, Dynamic Tension. Although the simulated results for the static tension test configurations fell into two groups with similarly modeled end conditions (\#1-3 


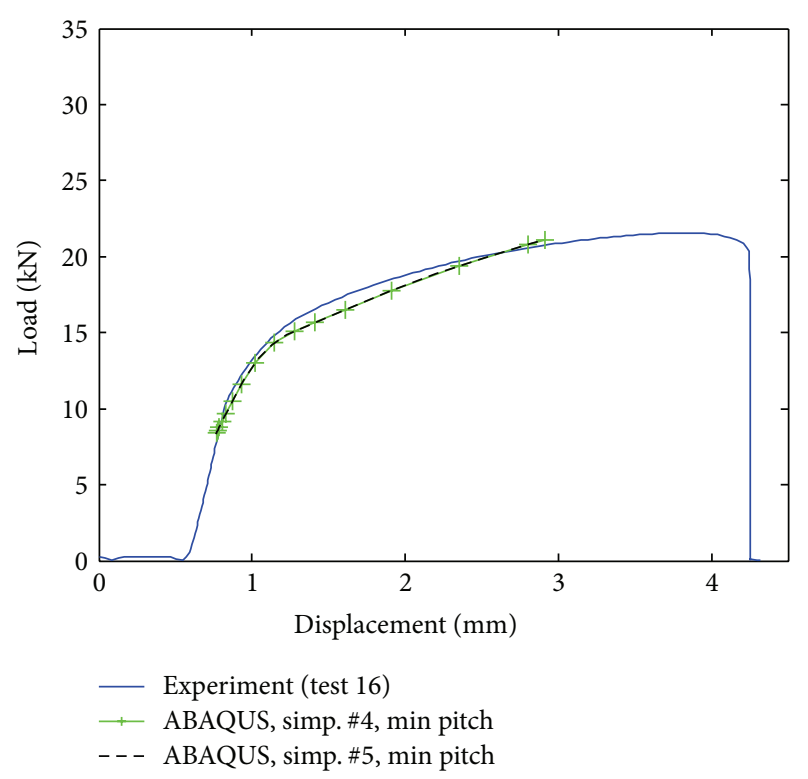

FIGURE 11: Force-displacement results for static tension test, simplified model \#4-5.

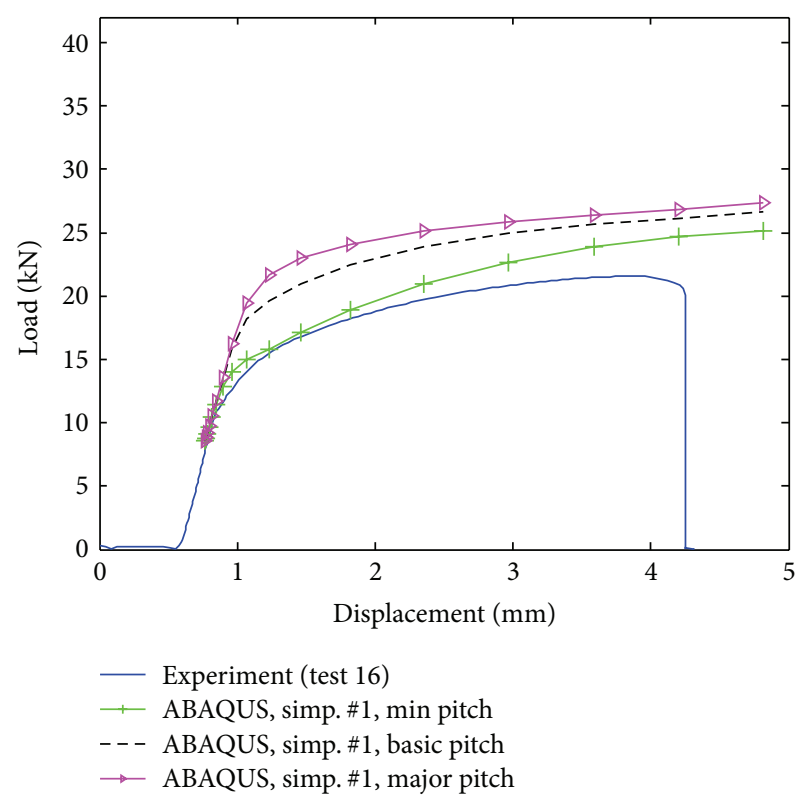

FIGURE 12: Force-displacement results for static tension test, simplified model \#1, using diameter values equal to minimum, basic, and maximum thread pitch in the threaded region.

and \#4-5), it is more appropriate to sort the simulated results for the dynamic tension tests into three groups. Figure 15 depicts results from simplified models \#1-3, together with the test data and shows that results from simplified models \#12 are very similar to one another but that they differ from results using simplified model \#3.

Simplified models \#1-2 and \#3 have been plotted against test data separately in Figures 16 and 17, respectively. Simplified models \#1-2 produced results that were very similar to one another, as would be expected since both models employed kinematic coupling to transfer bolt forces to the plates comprising the bolted joint.

The differences in response between the two groups can be attributed to their differences in end constraints. For simplified models \#1-2, the bolt body end nodes essentially stay in place in a relative sense. In simplified model \#1, the translational degrees of freedom of the perimeter nodes of the solid elements at the edge of the through hole are kinematically coupled to the displacements of the bolt body end node. Similarly, simplified model \#2 (MPC, type BEAM) provides multiple rigid beams between the bolt body end node and the perimeter nodes at the edge of the through hole, where no relative rotation is allowed between the bolt body end beam element and the notional rigid beams. However, simplified model \#3 does not include any rotational constraints on the relative motion between the bolt body and the linkages, creating a pinned end condition between the bolt body and the linking elements. This is not a problem for the static tension configuration, given the very controlled motion of the bolt during this test. However, for the dynamic tension case, the resulting motion of the bolt during the test is physically unrealistic because the resistance to rotational motion between the bolt head and shank is not captured by this model. This leads to a marked overprediction of tensile plate velocity at the accelerometer location for the first few peaks of the velocity response for simplified model \#3, seen in Figure 17.

Simulated results are very similar to each other for simplified models \#4-5, which used shell elements to represent the bolt head and where the bolt shank was tied to the nut via shared nodes in the endmost beam. Analogous to the static tension results, the presence of the bolt hole did not have much effect, as shown by the similarity in the simulated velocity results shown for each model in Figure 18.

It is interesting to note that models employing a shell element-based head appeared to produce velocity results that were more modulated than the test data in contrast with the other simplified models. This was also the case for the detailed model results, as seen in Figure 14. In fact, the detailed model and simplified models \#4-5 produced results very similar to one another, as shown in Figure 19. This modulation is thought to result from applying the velocity inputs from the interface plate directly to the test fixture rather than explicitly modeling the interface plate (and its interaction with the base fixture).

For all of the simplified models, contact was not included between the beam elements representing the bolt shank and the surface of the through hole. In the dynamic tension tests, this modeling assumption led to violations of physical bolt clearance effects. To briefly investigate this, an analysis was run with simplified model \#4 where contact was included between the beam elements representing the bolt shank and the surface of the through hole and it was found that inclusion of this contact did not have an appreciable effect on system response at the accelerometer location. Despite the exclusion of bolt clearance effects, all simplified models were able to produce results that correlated well with test data in both static and dynamic test configurations. 


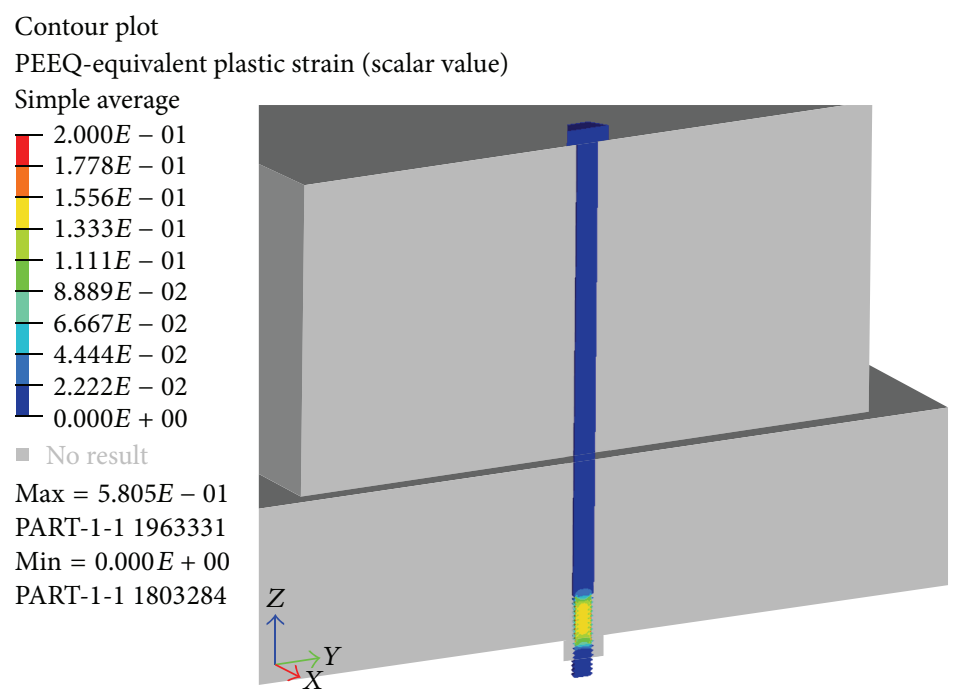

FIGURE 13: Contours of effective plastic strain at $t=150 \mathrm{~ms}$, detailed dynamic tension model.

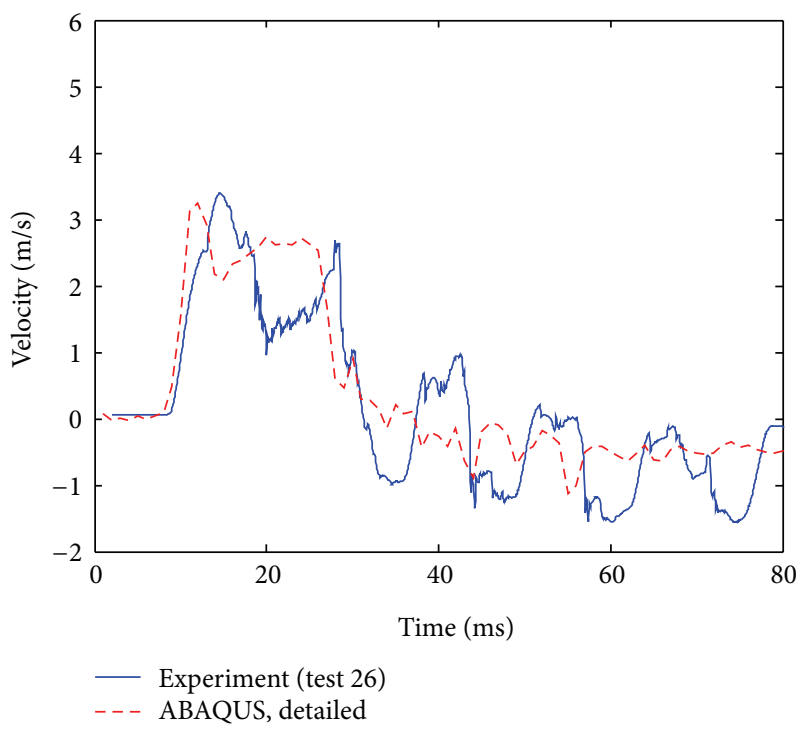

FIgURE 14: Velocity results for dynamic tension test, detailed model.

5.3. Russell Comprehensive Error. The Russell comprehensive error metric, which calculates variations in magnitude and phase between two transient data sets, was used to quantify the correlation between the experimental and simulated velocity data. The phase (RP) and magnitude (RM) Russell error metrics were used to calculate a comprehensive (RC) Russell error metric as follows [22]:

$$
\begin{gathered}
\mathrm{RP}=\frac{1}{\pi} \cos ^{-1}\left(\frac{\sum c_{i} m_{i}}{\sqrt{\sum c_{i}^{2} \sum m_{i}^{2}}}\right), \\
\mathrm{RM}=\operatorname{sign}(m) \log _{10}(1+|m|), \\
\mathrm{RC}=\sqrt{\frac{\pi}{4}\left(\mathrm{RM}^{2}+\mathrm{RP}^{2}\right) .}
\end{gathered}
$$

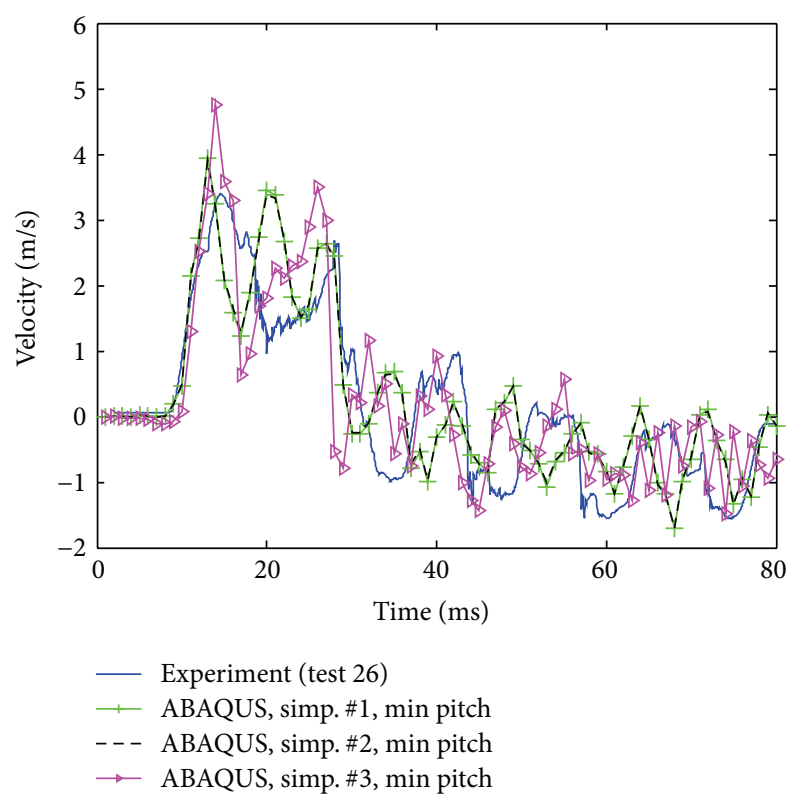

FIGURE 15: Velocity results for dynamic tension test, simplified model \#1-3.

In (1), $c_{i}$ and $m_{i}$ represent the calculated and measured responses, respectively. In the context of a comparison of simulated and experimental velocity data for a certain data set, subjective measures of correlation have been tied to set values of the Russell comprehensive error metric [22]. These subjective measures of correlation were "excellent," "acceptable," or "poor," where these levels are defined as excellent, $\mathrm{RC} \leq 0.15$; acceptable, $0.15<\mathrm{RC} \leq 0.28$; and poor, $\mathrm{RC}>0.28$ [22].

The Russell comprehensive error metric was calculated for all of the dynamic tension cases. Comparisons were made between the experimental data and the numerical data and the results are listed in Table 1 . Per the subjective measures 


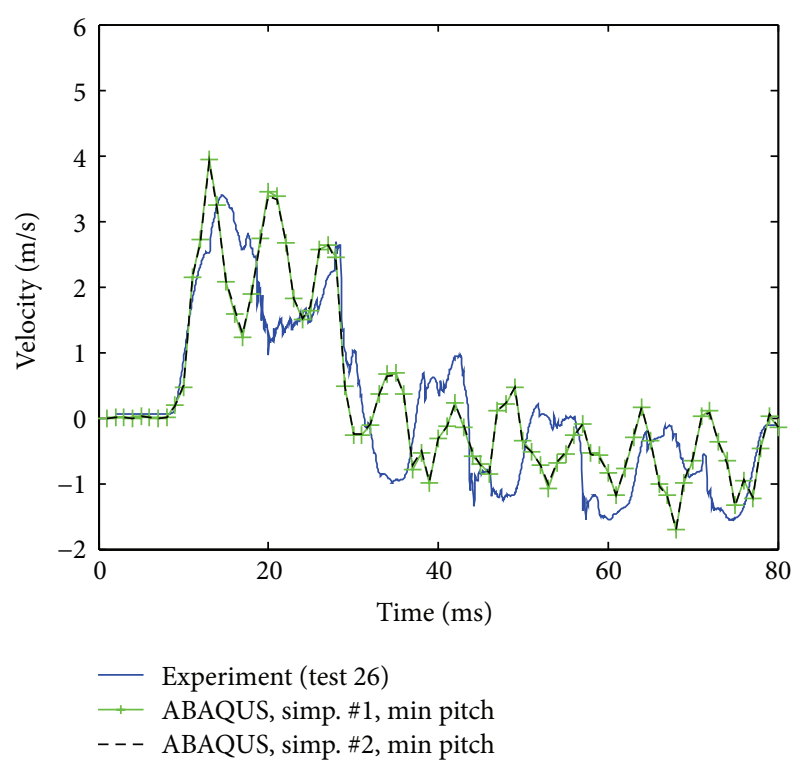

FIGURE 16: Velocity results for dynamic tension test, simplified model \#1-2.

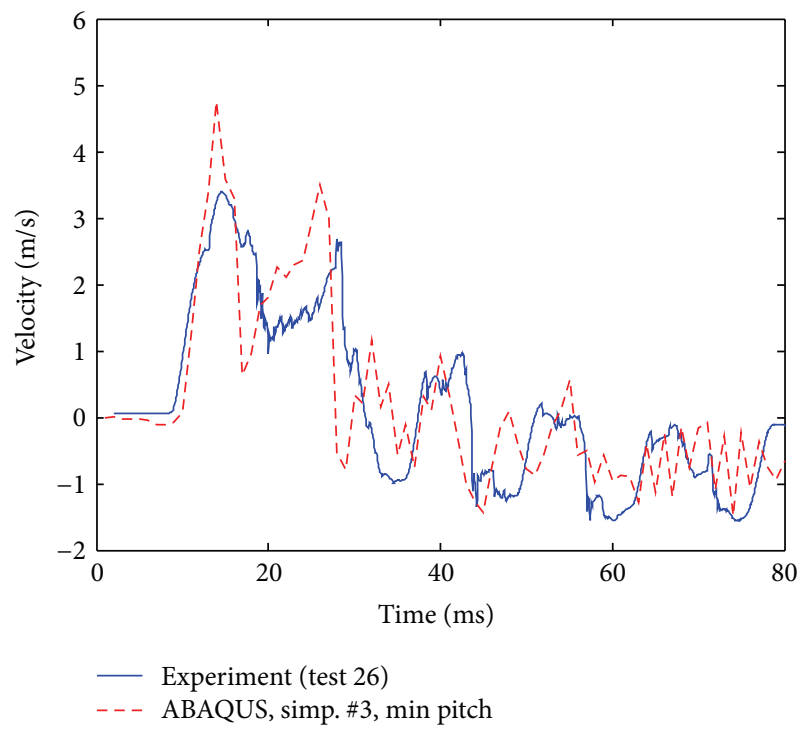

FIGURE 17: Velocity results for dynamic tension test, simplified model \#3.

TABLE 1: Russell comprehensive error (RC) results.

\begin{tabular}{lccc}
\hline Case & $\begin{array}{c}\text { Measured data, } \\
m_{i}\end{array}$ & $\begin{array}{c}\text { Calculated data, } \\
c_{i}\end{array}$ & RC \\
\hline Dynamic tension & Experiment & ABAQUS, detailed & 0.18 \\
Dynamic tension & Experiment & ABAQUS, simplified \#1 & 0.19 \\
Dynamic tension & Experiment & ABAQUS, simplified \#2 & 0.19 \\
Dynamic tension & Experiment & ABAQUS, simplified \#3 & 0.19 \\
Dynamic tension & Experiment & ABAQUS, simplified \#4 & 0.17 \\
Dynamic tension & Experiment & ABAQUS, simplified \#5 & 0.18 \\
\hline
\end{tabular}

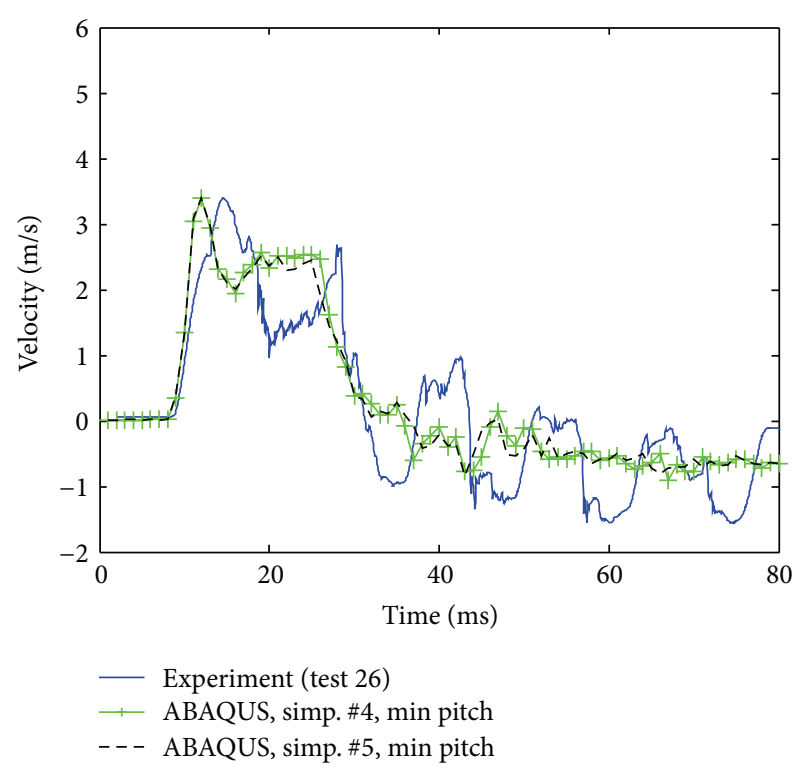

FIGURE 18: Velocity results for dynamic tension test, simplified model \#4-5.

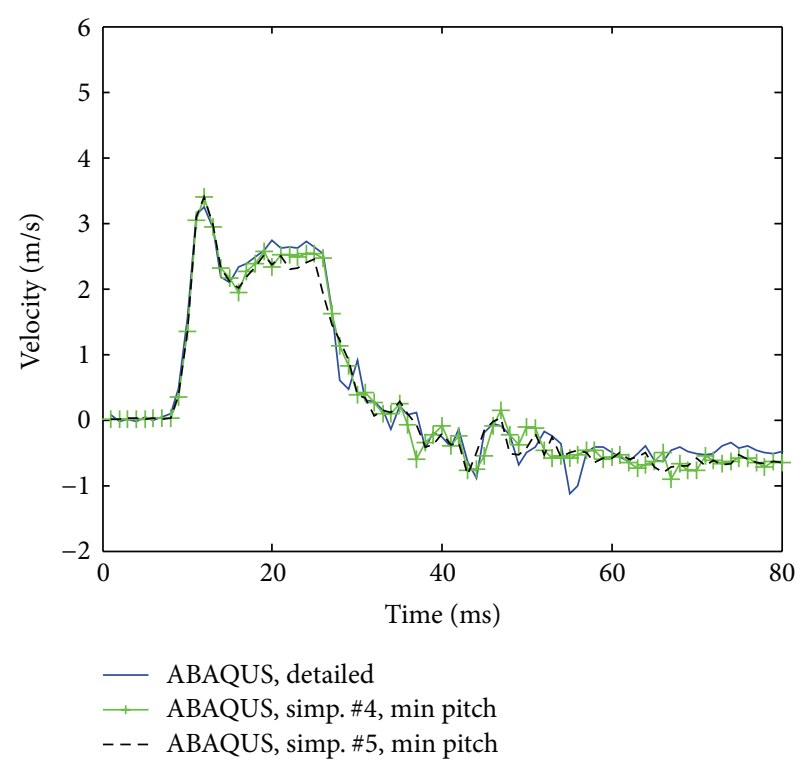

FIGURE 19: Velocity results for dynamic tension test, detailed model and simplified model \#4-5.

of correlation [22], all finite element approaches used to model the bolt produced "acceptable" results. The detailed model and simplified approaches \#4 and \#5, which used shell elements to represent the bolt head and with shared nodes to anchor the bolt body to the nut, produced results with slightly superior correlation with the data, but all modeling approaches were comparable in terms of correlation with test data.

\section{Conclusions}

In this paper, a variety of approaches were used to model the response of bolted connections involving single solid KMonel K500 bolts. Detailed finite element models, as well as 
five simplified finite element models, of the bolt were used to simulate physical experiments involving static and dynamic tension test configurations. The detailed finite element model was comprised of continuum elements while the simplified models involved beam elements to model the bolt body and various end conditions to transfer the bolt forces to the joint at each end of the bolt.

All simplified models employed beam elements of uniform circular cross-section to model the bolt body. Results from a parameter study showed that, in static tension test arrangements, simulations produced results that most closely matched experimental data when modeling the bolt shank with a diameter equal to the nominal bolt diameter and the threaded region with a diameter equal to the minimum (minor) thread pitch diameter, as compared to the basic or maximum (major) thread pitch diameter.

Models were validated against test data for the static and dynamic tension experiments. For the static test configurations, force-displacement results were compared to experimental load-displacement data, where the numerical results provided good correlation with the test data for detailed and simplified approaches. In the dynamic tests, simulated velocity results were compared to data from an accelerometer mounted onto one of the plates joined by the bolt. The Russell comprehensive error metric was used to quantify the correlation between the test data and simulated results produced using the various finite element modeling approaches. Russell error results showed that there is acceptable correlation between the experimental and the numerical velocity data for all models.

Future research can extend these models towards developing simplified finite element bolt representations capable of capturing shear loading as well as tensile loading. Despite the fact that bolt clearance effects were not included in the simplified models tested for this research, the tested simplified models all performed well for both static and dynamic tension configurations. However, the nature of shear loading will necessitate the inclusion of bolt clearance effects for accurate representation of bolt shear response using simplified means.

\section{Conflict of Interests}

The authors declare that there is no conflict of interests regarding the publication of this paper.

\section{Acknowledgments}

This work was supported by internal basic and applied research funding (NUWCDIVNPT). The DoD HPC Modernization Program supported this project by supplying supercomputer time at the US Army Engineer Research and Development Center. The authors would like to acknowledge the entire Chief Technology Office at NUWCDIVNPT.

\section{References}

[1] Y. Bao, S. K. Kunnath, S. El-Tawil, and H. S. Lew, "Macromodelbased simulation of progressive collapse: RC frame structures,"
Journal of Structural Engineering, vol. 134, no. 7, pp. 1079-1091, 2008.

[2] K. Khandelwal, S. El-Tawil, S. K. Kunnath, and H. S. Lew, "Macromodel-based simulation of progressive collapse: steel frame structures," Journal of Structural Engineering, vol. 134, no. 7, pp. 1070-1078, 2008.

[3] F. Sadek, J. Main, and H. S. Lew, "Testing and analysis of steel beam-column assemblies under column removal scenarios," in Proceedings of the ASCE Structures Congress, CD-ROM, ASCE, Reston, Va, USA, 2009.

[4] F. Sadek, S. El-Tawil, and H. S. Lew, "Robustness of composite floor systems with shear connections: modeling, simulation, and evaluation," Journal of Structural Engineering, vol. 134, no. 11, pp. 1717-1725, 2008.

[5] K. Khandelwal, S. El-Tawil, and F. Sadek, "Progressive collapse analysis of seismically designed steel braced frames," Journal of Constructional Steel Research, vol. 65, no. 3, pp. 699-708, 2009.

[6] J. Main and F. Sadek, "Development of 3D models of steel moment-frame buildings for assessment of robustness and progressive collapse vulnerability," in Proceedings of the ASCE Structures Congress, CD-ROM, ASCE, Reston, Va, USA, 2009.

[7] Y. Luan, Z.-Q. Guan, G.-D. Cheng, and S. Liu, "A simplified nonlinear dynamic model for the analysis of pipe structures with bolted flange joints," Journal of Sound and Vibration, vol. 331, no. 2, pp. 325-344, 2012.

[8] Y.-D. Kwon, H.-W. Kwon, J.-H. Hwangbo, and S.-H. Jang, "Finite element modeling for static and dynamic analysis of structures with bolted joint," Key Engineering Materials, vol. 306-308, pp. 547-552, 2006.

[9] J. Kim, J.-C. Yoon, and B.-S. Kang, "Finite element analysis and modeling of structure with bolted joints," Applied Mathematical Modelling, vol. 31, no. 5, pp. 895-911, 2007.

[10] Y. Shi, M. Wang, and Y. Wang, "Analysis on shear behavior of high-strength bolts connection," International Journal of Steel Structures, vol. 11, no. 2, pp. 203-213, 2011.

[11] M. A. McCarthy, C. T. McCarthy, V. P. Lawlor, and W. F. Stanley, "Three-dimensional finite element analysis of single-bolt, single-lap composite bolted joints: part I-model development and validation," Composite Structures, vol. 71, no. 2, pp. 140-158, 2005.

[12] C. T. McCarthy and M. A. McCarthy, "Three-dimensional finite element analysis of single-bolt, single-lap composite bolted joints. Part II. Effects of bolt-hole clearance," Composite Structures, vol. 71, no. 2, pp. 159-175, 2005.

[13] K. E. Behan, E. L. Guzas, J. R. Milburn, and S. M. Moss, "Finite element modeling of K-Monel bolts under static loading and dynamic shock loading," Shock and Vibration, vol. 20, no. 3, pp. 575-589, 2013.

[14] K. E. Behan, C. Pinero Pabon, E. L. Guzas, J. R. Milburn, and S. M. Moss, "Results of the static and dynamic testing for the improved fastener modeling: phase II testing," Tech. Rep. NUWC-NPT-TM2010/100, 2010.

[15] Military Specification MIL-S 901D, Shock Tests, H.I. (HighImpact), Shipboard Machinery, Equipment, and Systems, Requirements for ( DoD, 17 March 1989).

[16] Abaqus 6.9 Analysis User's Manual, vol. 1-5, Dassault Systems, 2009.

[17] Abaqus 6.9 Keywords Manual, vol. 1-2, Dassault Systèmes, Waltham, Mass, USA, 2009.

[18] Dassault Systems, Abaqus 6.9 Theory Manual, Dassault Systems, Waltham, Mass, USA, 2009. 
[19] M. A. Crisfield, "A fast incremental/iterative solution procedure that handles "snap-through"', Computers and Structures, vol. 13, no. 1-3, pp. 55-62, 1981.

[20] E. Ramm, "Strategies for tracing nonlinear responses near limit points," in Nonlinear Finite Element Analysis in Structural Mechanics, W. Wunderlich, E. Stein, and K. J. Bathe, Eds., pp. 63-89, Springer, New York, NY, USA, 1981.

[21] E. Oberg, F. D. Jones, and H. L. Horton, Machinery's Handbook, Industrial Press, New York, NY, USA, 23rd edition, 1988.

[22] D. M. Russell, "Error measures for comparing transient data, part I: development of a comprehensive error measure, part II: error measures case study," in Proceedings of the 68th Shock and Vibration Symposium, Hunt Valley, Md, USA, November 1997. 

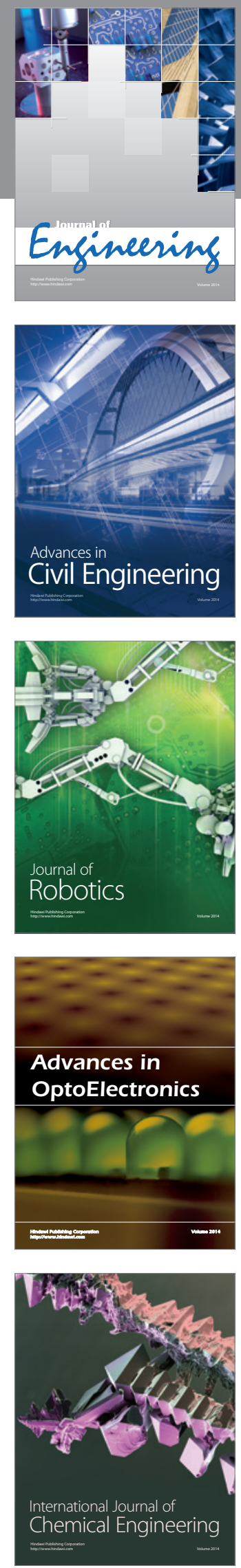

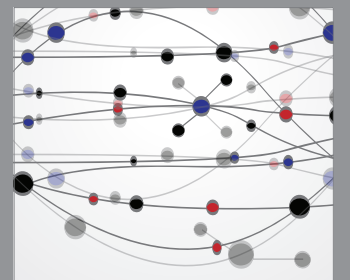

The Scientific World Journal
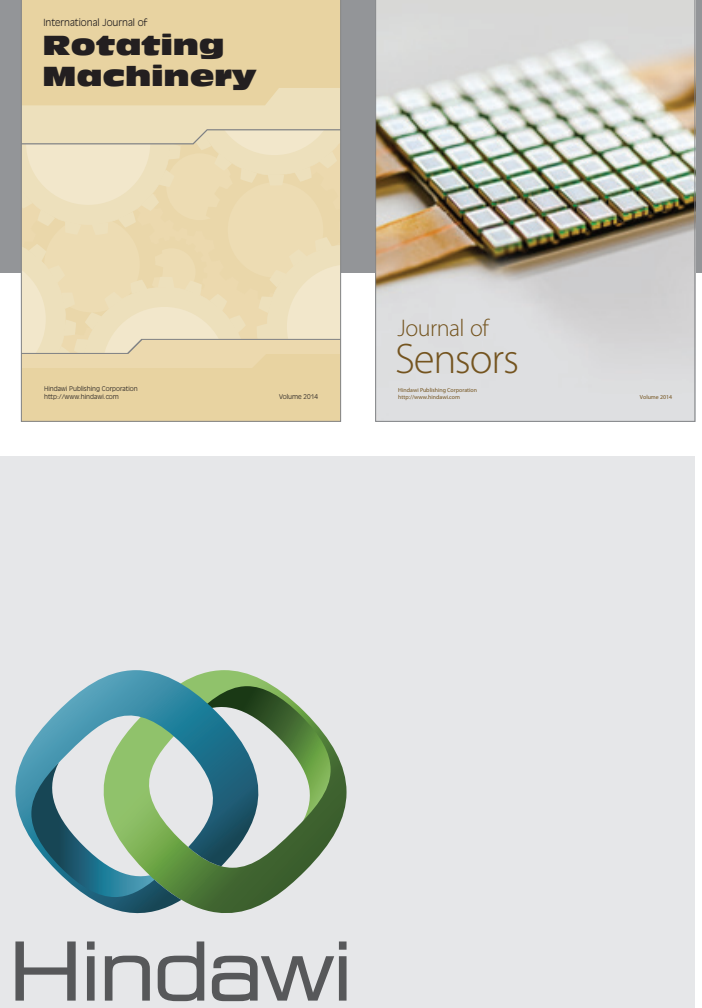

Submit your manuscripts at http://www.hindawi.com
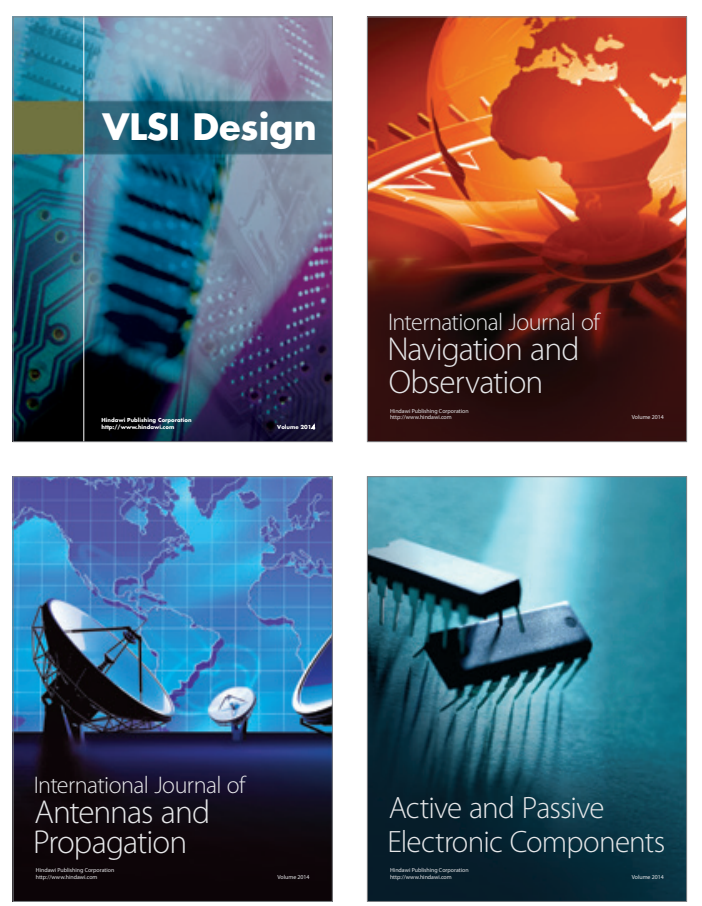
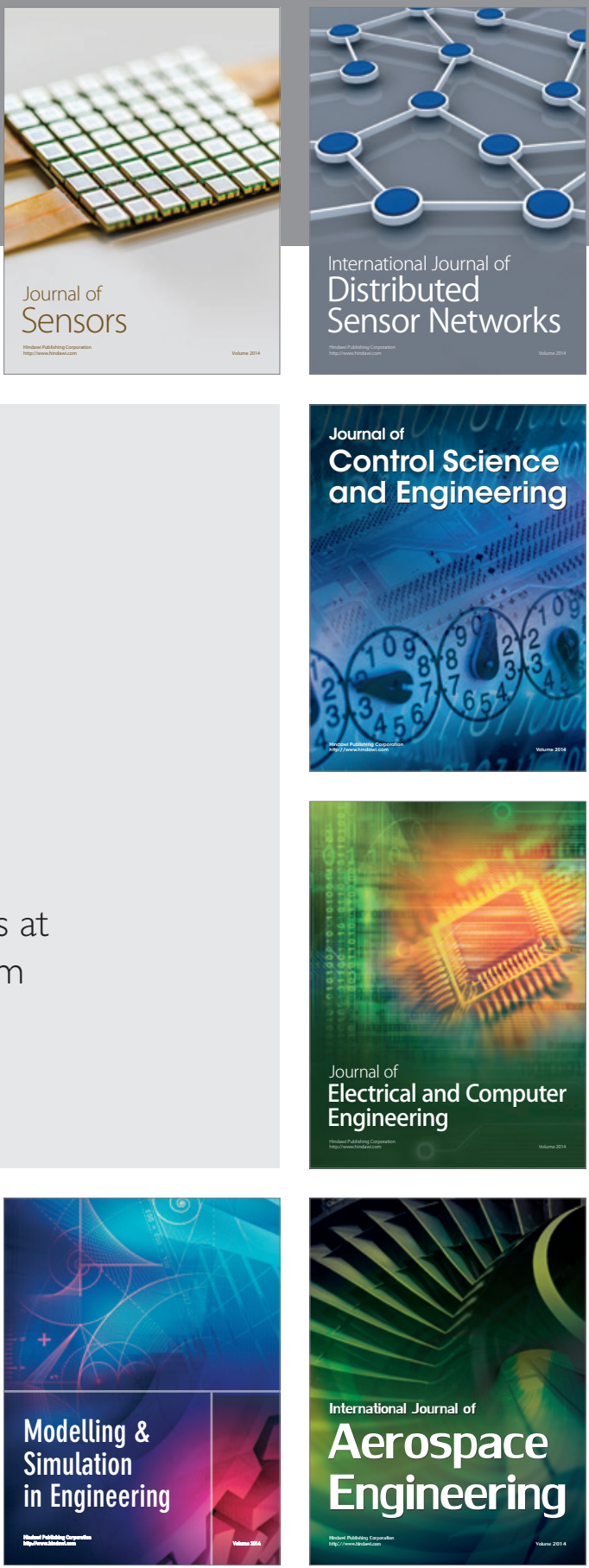

Journal of

Control Science

and Engineering
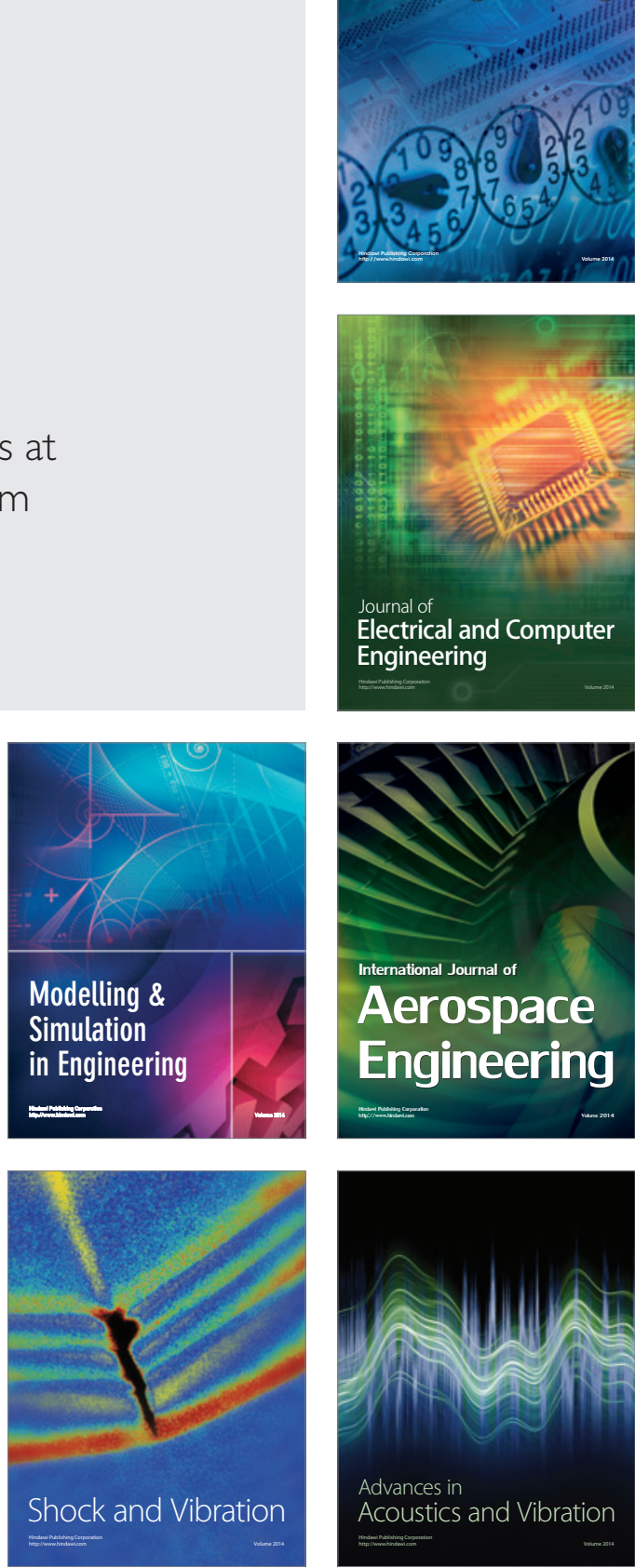